\title{
Prevalence and dynamics of clonal hematopoiesis caused by leukemia-associated mutations in elderly individuals without hematologic disorders
}

\author{
Danica Midic ${ }^{1}$ Jenny Rinke ${ }^{1}$ Florian Perner ${ }^{1} \cdot$ Violetta Müller $^{1} \cdot$ Anna Hinze $^{1} \cdot$ Frank Pester $^{2} \cdot$ Jürgen Landschulze $^{2}$. \\ Jana Ernst ${ }^{3} \cdot$ Bernd Gruhn $^{3} \cdot$ Georg Matziolis ${ }^{4} \cdot$ Florian H. Heidel $\mathbb{D}^{1,5} \cdot$ Andreas Hochhaus $^{1} \cdot$ Thomas Ernst $^{1}$
}

Received: 15 April 2020 / Revised: 29 April 2020 / Accepted: 11 May 2020 / Published online: 26 May 2020

(c) The Author(s) 2020. This article is published with open access

\begin{abstract}
Clonal hematopoiesis is frequently observed in elderly people. To investigate the prevalence and dynamics of genetic alterations among healthy elderly individuals, a cohort of 50 people $>80$ years was genotyped for commonly mutated leukemia-associated genes by targeted deep next-generation sequencing. A total of 16 somatic mutations were identified in $13 / 50(26 \%)$ individuals. Mutations occurred at low variant allele frequencies (median 11.7\%) and remained virtually stable over 3 years without development of hematologic malignancies in affected individuals. With DNMT3A mutations most frequently detected, another cohort of 160 healthy people spanning all age groups was sequenced specifically for $D N M T 3 A$ revealing an overall mutation rate of $6.2 \%$ (13/210) and an age-dependent increase of mutation prevalence. A significant difference $(p=0.017)$ in the DNMT3A expression pattern was detected between younger and healthy elderly people as determined by qRT-PCR. To evaluate the selection of clonal hematopoietic stem cells (HSCs), bone marrow of two healthy individuals with mutant DNMT3A was transplanted in a humanized mouse model. Xenografts displayed stable kinetics of DNMT3A mutations over 8 months. These findings indicate that the appearance of low-level clones with leukemia-associated mutations is a common age-associated phenomenon, but insufficient to initiate clonal selection and expansion without the additional influence of other factors.
\end{abstract}

\section{Introduction}

Clonal hematopoiesis $(\mathrm{CH})$ is defined as the clonal expansion of blood cells derived from a single hematopoietic stem

Supplementary information The online version of this article (https:// doi.org/10.1038/s41375-020-0869-y) contains supplementary material, which is available to authorized users.

Thomas Ernst

thomas.ernst@med.uni-jena.de

1 Abteilung Hämatologie und Internistische Onkologie, Klinik für Innere Medizin II, Universitätsklinikum Jena, Jena, Germany

2 HausArztZentrum, Kahla, Germany

3 Klinik für Kinder- und Jugendmedizin, Universitätsklinikum Jena, Jena, Germany

4 Orthopädische Klinik der Waldkliniken Eisenberg, Eisenberg, Germany

5 Leibniz Institute on Aging, Fritz-Lipmann-Institute, Jena, Germany cell. Recent studies suggest that $\mathrm{CH}$ is an age-related event, triggered by somatic mutations in leukemia-associated genes. While acquisition of these mutations is considered one of the earliest events in the pathogenesis of different hematologic malignancies, clonal hematopoiesis driver mutations (CHDMs) may be present and cause $\mathrm{CH}$ without any clinically distinct phenotype. Three recent wholeexome-sequencing analyses of large populations have revealed age-related hematopoietic clones in apparently healthy individuals, driven by mutations of genes recurrently mutated in myeloid neoplasms and associated with increased risk of hematologic cancer and cardiovascular diseases [1-3]. $\mathrm{CH}$ with somatic mutations was observed in $10 \%$ of individuals older than 65 years of age, but only in $1 \%$ of those younger than 50 years of age [2]. Furthermore, CHDMs were detected in $10 \%$ of individuals older than 70 years and in about $20 \%$ of those older than 90 years [3]. The most frequently mutated genes include DNMT3A, TET2, $J A K 2$, and $A S X L 1$. Based on these three large studies, Steensma et al. proposed the term CHIP (clonal hematopoiesis of indeterminate potential) for individuals harboring 
somatic mutations of genes frequently mutated in hematologic malignancies with a variant allele frequency $(\mathrm{VAF}) \geq$ $2 \%$, in the absence of definitive morphologic and clinical evidence of a hematologic malignancy [4].

The fact that patients with hematologic malignancies and healthy individuals share a common set of genetic mutations highlights the need to further elucidate the prevalence and kinetics of these mutations within the general population and to understand the underlying mechanisms of clonal selection and stability. This study investigated the prevalence and long-term dynamics of genetic alterations in leukemia-associated genes among elderly individuals without hematologic disorders or cancer. As DNMT3A mutations were most frequently detected, blood samples of 160 individuals of all ages of the general population were analyzed for DNMT3A mutations. Additionally, relative DNMT3A expression levels of younger and older individuals were compared to investigate age-related differences beyond the mutation status. A model of DNMT3A activity in hematopoietic stem cells (HSCs) proposed by Challen et al. suggests the crucial role of DNMT3A in balancing differentiation and self-renewal of HSCs by upregulation of HSC multipotency genes and downregulation of differentiation genes. Lack of DNMT3A function was shown to lead to altered methylation patterns reminiscent of those observed in human malignancies and an increased expression of genes normally restricted to stem cells [5]. Considering the key epigenetic regulatory role and the frequent involvement of DNMT3A in human malignancies, the study presented here finally investigated clonal expansion using bone marrow of healthy individuals with mutant DNMT3A in a humanized mouse model.

\section{Materials and methods}

\section{Cohorts of healthy individuals}

The first cohort included 50 elderly individuals (male, $n=$ 21; median age 84 years, range $80-90$ years). Peripheral blood (PB) samples were taken and sequenced for a panel of commonly mutated leukemia-associated genes. The second cohort of 160 healthy people $<80$ years of age was specifically sequenced for DNMT3A mutations (male, $n=77$; median age 40 years, range $0-79$ years). Total leukocytes were isolated from PB after red cell lysis. As a source of constitutional DNA, oral mucosa cells were obtained from all patients using buccal swabs. All procedures were in accordance with the ethical standards of the institutional research committee and with the Declaration of Helsinki. Informed consent was obtained from all individuals included in the study.

\section{DNA and RNA extractions}

Genomic DNA (gDNA) was isolated from PB leukocytes and oral mucosa cells using the QIAamp DNA Mini Kit (Qiagen, Hilden, Germany) according to the manufacturer's recommendations. For RNA isolation, $1 \mathrm{ml} \mathrm{Trizol}^{\circledR}$ reagent (Thermo Fisher Scientific, Waltham, MA, USA) was added to $2 \times 10^{7}$ cells and mixed thoroughly. Subsequent RNA extraction was performed as described in the literature [6].

\section{Next-generation sequencing (NGS)}

Samples of 50 healthy elderly individuals were genotyped for a panel of 30 commonly mutated leukemia-associated genes by targeted deep NGS [7, 8], using the 454 GS Junior platform (Roche Diagnostics, Mannheim, Germany) at a sensitivity level of 5\%. Prior to sequencing, whole genome amplification (WGA) was performed using $20 \mathrm{ng}$ template gDNA and the Repli-g Ultra Fast Mini Kit (Qiagen) in accordance with manufacturer's instructions. Analyses covered genes involved in signaling, transcription, epigenetics, RNA splicing, and the cohesin complex. Another cohort of 160 healthy people $<80$ years of age was specifically sequenced for $D N M T 3 A$ mutations, using a customdesigned highly sensitive DNMT3A-specific deep NGS assay (sensitivity $1 \%$ ) covering the entire coding region of the DNMT3A gene (exons 2-23). For each NGS run $8 J A K 2$ p.V617F samples were generated and used as an external sensitivity control. PCR products were resolved on $3 \%$ agarose gels and visualized by staining with ethidium bromide. Mutations found in WGA samples were verified using gDNA isolated from leukocytes and buccal swabs to confirm the somatic origin of mutations, in a separate NGS run. All mutational percentages listed refer to the results found in gDNA. NGS data was analyzed with the GS Amplicon Variant Analyzer (AVA) software (version 2.7; Roche). The open access tools Protein Variation Effect Analyzer (PROVEAN) and Polymorphism Phenotyping v2 (PolyPhen-2) were used for evaluation of potential consequences of the identified mutations $[9,10]$.

\section{Expression analysis by quantitative real-time PCR (qRT-PCR)}

For DNMT3A gene expression analyses, cDNA synthesis was performed using M-MLV Reverse transcriptase (Invitrogen $\mathrm{GmbH}$, Karlsruhe, Germany) and a minimum of $1 \mu \mathrm{g}$ RNA. Analysis by qRT-PCR was performed according to standard protocols using SYBR Green I (Roche), DNMT3A as a target, and $\beta$-glucuronidase (GUSB) as a reference gene. The relative expression rate was calculated using the $\Delta \mathrm{Ct}$-method [11]. Primers were designed using primer3web 
Table 1 Somatic mutations in leukemia-associated genes within a cohort of 50 healthy elderly individuals.

\begin{tabular}{|c|c|c|c|c|c|c|c|c|}
\hline Sample number & Sex, age & Gene & $\begin{array}{l}\text { Variant } \\
\text { Ensemble }\end{array}$ & Protein & $\begin{array}{l}\% \text { Reads } \\
\text { displaying } \\
\text { variant gDNA }\end{array}$ & $\begin{array}{l}\% \text { Reads } \\
\text { displaying } \\
\text { variant } \\
\text { buccal cells }\end{array}$ & $\begin{array}{l}\% \text { Reads } \\
\text { displaying } \\
\text { variant gDNA } \\
\text { (2-year follow-up) }\end{array}$ & $\begin{array}{l}\% \text { Reads } \\
\text { displaying } \\
\text { variant gDNA } \\
\text { (3-year follow-up) }\end{array}$ \\
\hline$\# 5$ & Female, 86 & DNMT3A & c. $1403 \mathrm{~A}>\mathrm{G}$ & p.K468R & 5.53 & 0.00 & 5.42 & 4.85 \\
\hline \#9 & Male, 81 & $S R S F 2$ & $\begin{array}{l}\text { c.144_169del } \\
(26)\end{array}$ & p.Y50LfsX11 & 10.63 & 0.46 & 7.12 & 8.33 \\
\hline$\# 10$ & Male, 86 & $S F 3 B 1$ & c. $2098 \mathrm{~A}>\mathrm{G}$ & p.K700E & 6.56 & 0.00 & $\dagger$ & $\dagger$ \\
\hline \multirow[t]{2}{*}{ \#15 } & \multirow[t]{2}{*}{ Female, 83} & DNMT3A & c. $2644 \mathrm{C}>\mathrm{T}$ & p.R882C & 4.89 & 0.00 & 6.76 & - \\
\hline & & DNMT3A & c. $2711 \mathrm{C}>\mathrm{T}$ & p.P904L & 3.60 & 0.00 & 3.54 & - \\
\hline \multirow[t]{3}{*}{ \#21 } & \multirow[t]{3}{*}{ Male, 85} & $I D H 2$ & c. $418 \mathrm{C}>\mathrm{T}$ & p.R140W & 22.75 & 12.47 & 28.98 & 33.69 \\
\hline & & $S R S F 2$ & c. $284 \mathrm{C}>\mathrm{T}$ & p.P95L & 28.78 & 15.6 & 35.29 & 56.59 \\
\hline & & TET2 & c. $5618 \mathrm{~T}>\mathrm{C}$ & p.I1873T & 20.41 & 12.74 & 21.80 & 21.51 \\
\hline$\# 22$ & Female, 85 & DNMT3A & c. $1988 \mathrm{C}>\mathrm{T}$ & p.S663W & 1.04 & 0.00 & 1.02 & 0.86 \\
\hline$\# 24$ & Male, 81 & TP53 & c. $638 \mathrm{G}>\mathrm{A}$ & p.R213Q & 15.43 & 0.90 & 15.70 & 18.50 \\
\hline$\# 25$ & Male, 81 & DNMT3A & c. $2401 \mathrm{~A}>\mathrm{G}$ & p.M801V & 30.69 & 10.82 & 30.04 & 32.15 \\
\hline \#35 & Female, 86 & $N R A S$ & c. $35 \mathrm{G}>\mathrm{A}$ & p.G12D & 6.19 & 0.39 & 11.72 & - \\
\hline$\# 37$ & Female, 81 & DNMT3A & c. $1031 \mathrm{~T}>\mathrm{C}$ & p.L344P & 5.03 & 1.58 & 5.23 & 5.17 \\
\hline \#41 & Female, 82 & DNMT3A & c. $929 \mathrm{~T}>\mathrm{C}$ & p.I310T & 17.82 & 0.00 & 17.26 & 21.60 \\
\hline \#42 & Male, 85 & $U 2 A F 1$ & c. $101 \mathrm{C}>\mathrm{T}$ & p.S34F & 23.16 & 1.38 & $\dagger$ & $\dagger$ \\
\hline$\# 43$ & Female, 81 & DNMT3A & c. $1988 \mathrm{C}>\mathrm{T}$ & p.S663W & 12.67 & 0.00 & 14.38 & 18.80 \\
\hline
\end{tabular}

$\dagger$ Patient deceased.

(version 4.0.0). Primer sequences with the corresponding product size are shown in Table SI. Statistical analysis was performed using the Mann-Whitney nonparametric test, provided by GraphPad Prism v6.01 (GraphPad Software, Inc., San Diego, CA, USA).

\section{Patient-derived xenograft (PDX) model}

Bone marrow cells of two healthy elderly individuals (age 69 and 79 years) with $D N M T 3 A$ mutations were transplanted into a humanized mouse model. Primary bone marrow cells of elderly healthy donors were obtained from fractured hip bones after hemiarthroplasty following informed consent according to the Helsinki declaration (approved by the local ethics committee \#4753/04-16). Bone marrow cells were extracted from the bone, erythrolysed and cryopreserved in 1x freezing medium (80\% FBS + 10\% DMSO + 10\% IMDM medium). NOD.Cg-Prkde ${ }^{\text {scid }}$ Il2rg ${ }^{\text {tm1Wjl }} \mathrm{Tg}$ (CMV-IL3, CSF2, KITLG) 1Eav/MloySzJ (NSGS) were obtained from The Jackson Laboratory (Bar Harbor, ME, USA). Before transplantation, 8-12-week-old adult mice were irradiated with $2 \mathrm{~Gy}$ (single dose). Via the tail vein, $2 \times 10^{6}$ cells were injected intravenously. Engraftment of human cells (hCD45+) was analyzed by flow cytometry. Three mice were engrafted for each mutation. The DNMT3A mutations were previously detected using the MiniSeq System (TruSight Myeloid Sequencing Panel, VariantStudio Software 3.0, Illumina, San Diego, USA). For analysis, murine bone marrow cells were isolated from the femurs as previously described [12]. Bone marrow samples were then assessed for clonal selection of the known DNMT3A mutations by pyrosequencing, according to standard protocols. Sequencing primers are listed in the Table SII.

\section{Results}

\section{Somatic mutations in healthy elderly individuals}

A total of 16 somatic mutations in leukemia-associated genes were identified in 13 of $50(26 \%)$ hematologically normal elderly individuals (Table 1). One subject presented with two and another subject with three mutations of different genes. Ten of 16 mutations $(62.5 \%)$ affected epigenetic modifier genes (DNMT3A, $n=8 ; T E T 2, n=1 ; I D H 2$, $n=1$ ), four somatic mutations affected genes involved in the RNA splicing machinery (SRSF2, $n=2 ; S F 3 B 1, n=1$; $U 2 A F 1, n=1)$. Mutations in TP53 and NRAS were identified in two individuals. Detected mutations were verified on non-amplified gDNA by performing a separate NGS run, whilst the somatic origin was confirmed using corresponding buccal swab gDNA. All but one mutation were missense mutations with cytosine to thymine transitions being the most common base pair change $(n=7)$. Mutations occurred at low VAF with a median of $11.7 \%$ (range, $1.0-30.7 \%$ ), indicating that mutations were present in only a subset of blood cells. 


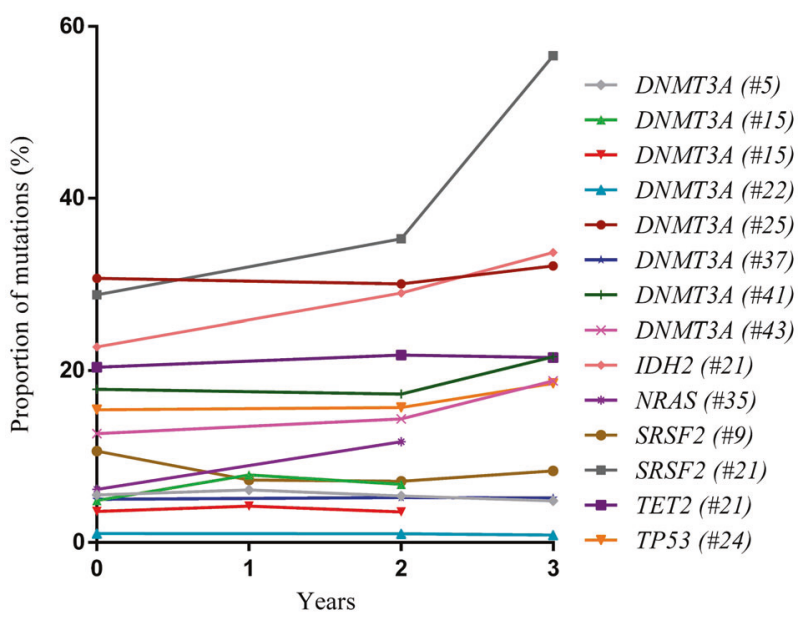

Fig. 1 Dynamics of somatic mutations detected in 50 healthy elderly individuals during a 3-year follow up period. Two subjects with mutations in splicing factor genes $S F 3 B 1$ and $U 2 A F 1$ died. For two patients (\#15 and \#35) the 3-year follow-up samples were not available.

\section{Mutation dynamics and clinical outcome during a 3-year period}

Mutation kinetics remained virtually stable over 3 years, with a median VAF of $13.1 \%$ (range, $1.0-35.3 \%$ ) after a 2year follow-up and a median VAF of $18.8 \%$ after a 3-year follow-up (range, 0.9-56.6\%) (Table 1). The mutations' dynamics during the 3-year period are depicted in Fig. 1. During the 3-year follow-up observation, two subjects with mutations in splicing factor genes died. One subject with an SF3B1 mutation developed pancreatic cancer, the other subject harboring a $U 2 A F 1$ mutation died due to a stroke. All other individuals with mutations were alive without any evidence for a hematologic or oncologic disorder.

\section{Age-associated increase of somatic DNMT3A mutations in healthy individuals}

Since DNMT3A mutations were the most common mutations identified in elderly individuals (8/16 detected mutations), we sought to study the age-dependent prevalence of DNMT3A mutations in more detail. Therefore, an additional cohort of 160 individuals was investigated, including healthy people $<80$ years of age (male, $n=77$; median age 40 years, range $0-79$ years) using a custom-designed highly sensitive DNMT3A-specific deep NGS assay (sensitivity $1 \%$ ), covering the complete coding region of the DNMT3A gene (exons 2-23). The youngest individual with a DNMT3A mutation was a 28 years old female. Mutations occurred at low VAFs with a median of $8.2 \%$ (range, 1.5-37.3\%). No DNMT3A mutation was detected in 40 analyzed PB samples of children and adolescents (0-19 years). Somatic DNMT3A mutations were found in $2 / 40$

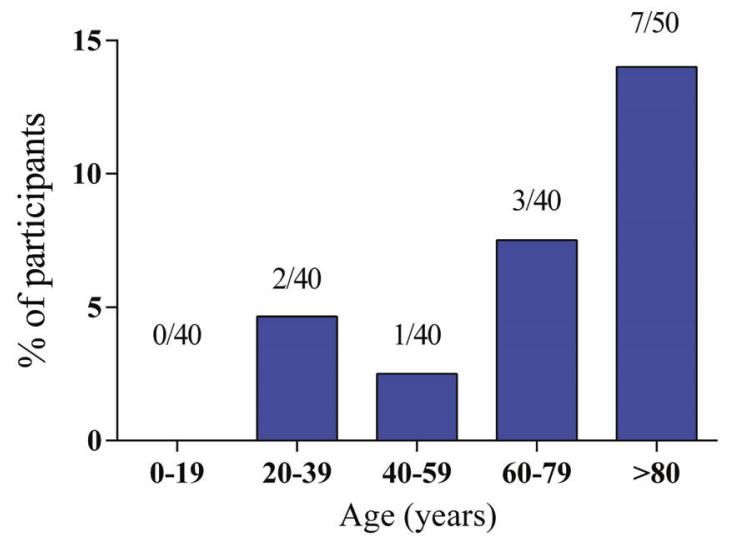

Fig. 2 Age-associated increase of $D N M T 3 A$ mutations in healthy individuals. Frequency of $D N M T 3 A$ mutations was analyzed within five age cohorts $(0-19 ; 20-39 ; 40-59 ; 60-79 ;>80$ years) by a highly sensitive $D N M T 3 A$-specific deep next-generation sequencing assay.

(5.0\%) individuals with an age of 20-39 years, 1/40 subjects $(2.5 \%)$ between 40 and 59 years, and in $3 / 40$ subjects (7.5\%) between 60 and 79 years of age (Fig. 2). Overall, six somatic DNMT3A mutations were identified in 6 of 160 $(3.8 \%$ ) individuals (Table 2$)<80$ years of age. In comparison, the mutation frequency of DNMT3A in healthy elderly persons ( $\geq 80$ years) was with $14 \%$ (7/50) much higher. The DNMT3A mutation rate in the whole cohort of healthy individuals, both younger and elderly, was $6.2 \%(13 / 210)$ in total.

\section{DNMT3A mRNA expression in healthy individuals}

DNMT3A mRNA expression was analyzed by qRT-PCR in the previously sequenced cohort of younger healthy individuals (20-39 years, $n=40)$ and healthy elderly ( $\geq 80$ years, $n=48)$. Significantly lower expression $(* p=0.017)$ was found in healthy elderly people (Fig. 3a). Taking sequencing results of these two groups into consideration, a marginal albeit not significant difference $(p=0.14)$ was found in expression levels comparing individuals carrying wild type DNMT3A (DNMT3A $\left.A^{w t}, n=79\right)$ with those carrying DNMT3A somatic mutations $\left(D N M T 3 A^{m u t}, n=9\right)$ (Fig. 3b).

\section{Stable kinetics of DNMT3A mutations in a PDX model}

To further investigate the clonal selection of DNMT3A mutations, transplantation of bone marrow cells of two healthy elderly individuals with different somatic DNMT3A mutations in a PDX model were performed. Mutations were detected using the MiniSeq System (Illumina), as a part of a subproject analyzing CHDM in bone marrow samples of healthy individuals. Detected DNMT3A mutations are 
Table 2 Somatic DNMT3A mutations within a cohort of 160 healthy younger individuals.

\begin{tabular}{|c|c|c|c|c|c|c|c|c|c|}
\hline Sample number & Sex, age & DNMT3A exon & $\begin{array}{l}\text { Variant } \\
\text { Ensemble }\end{array}$ & Protein & Ensemble entry & $\begin{array}{l}\text { PolyPhen-2 } \\
\text { prediction }\end{array}$ & $\begin{array}{l}\text { PROVEAN } \\
\text { prediction }\end{array}$ & $\begin{array}{l}\% \text { Reads } \\
\text { displaying } \\
\text { variant gDNA }\end{array}$ & $\begin{array}{l}\text { \% Reads } \\
\text { displaying } \\
\text { variant } \\
\text { buccal cells }\end{array}$ \\
\hline \#72 & Female, 28 & 23 & c. $2645 \mathrm{G}>\mathrm{A}$ & p.R882H & $\begin{array}{l}\text { Somatic mutation found in } \\
\text { human cancers } \\
\text { (COSM52944) and } \\
\text { pathogenic SNP } \\
\text { (rs147001633) }\end{array}$ & $\begin{array}{l}\text { Probably } \\
\text { damaging }\end{array}$ & Deleterious & 18.88 & 6.10 \\
\hline \#76 & Male, 31 & 14 & c. $1651 \mathrm{~A}>\mathrm{G}$ & p.N551D & Not displayed in Ensemble & $\begin{array}{l}\text { Probably } \\
\text { damaging }\end{array}$ & Deleterious & 8.49 & 0.00 \\
\hline \#96 & Male, 49 & 19 & c. $2309 \mathrm{C}>\mathrm{T}$ & p.S770L & $\begin{array}{l}\text { Somatic mutation found in } \\
\text { human cancers } \\
\text { (COSM231549) and SNP } \\
\text { (rs758845779) }\end{array}$ & $\begin{array}{l}\text { Probably } \\
\text { damaging }\end{array}$ & Deleterious & 2.43 & 0.00 \\
\hline \#149 & Male, 63 & 23 & c. $2644 \mathrm{C}>\mathrm{T}$ & p.R882C & $\begin{array}{l}\text { Somatic mutation found in } \\
\text { human cancers } \\
\text { (COSM53042) and } \\
\text { pathogenic SNP } \\
\text { (rs377577594) }\end{array}$ & $\begin{array}{l}\text { Probably } \\
\text { damaging }\end{array}$ & Deleterious & 8.00 & 0.00 \\
\hline$\# 151$ & Female, 69 & 8 & c. $862 \mathrm{delC}$ & p.R288Gfs*28 & Not displayed in Ensemble & $\begin{array}{l}\text { No } \\
\text { predictions } \\
\text { available }\end{array}$ & $\begin{array}{l}\text { No } \\
\text { predictions } \\
\text { available }\end{array}$ & 37.30 & 0.00 \\
\hline \#158 & Female, 74 & 20 & c. $2381 \mathrm{~T}>\mathrm{C}$ & p.F794S & Not displayed in Ensemble & $\begin{array}{l}\text { Probably } \\
\text { damaging }\end{array}$ & Deleterious & 1.54 & 0.00 \\
\hline
\end{tabular}

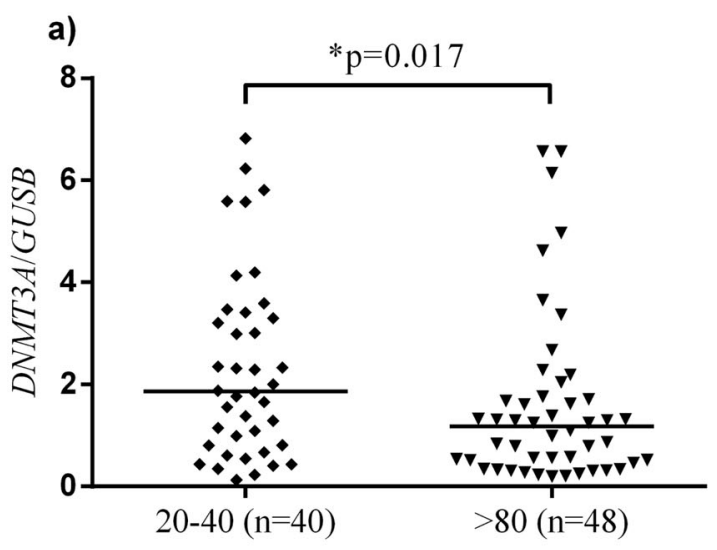

Age (years)

b)

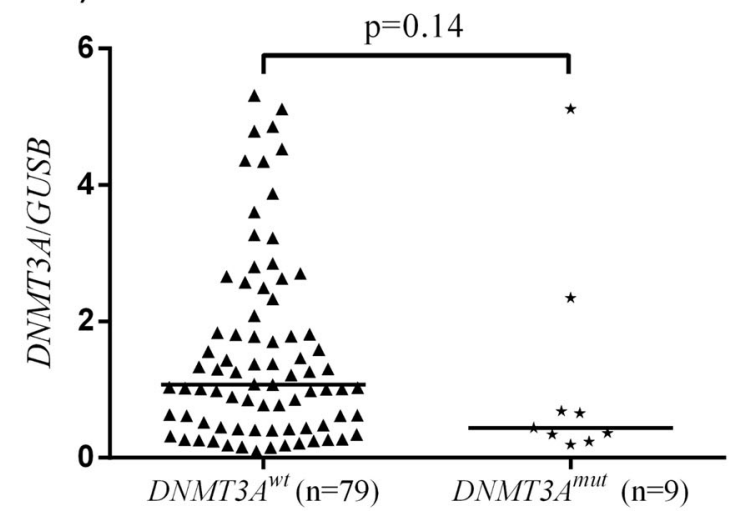

Fig. 3 DNMT3A mRNA expression in healthy individuals. a Ageassociated decrease of DNMT3A expression (median value depicted; $* p=0.017)$. b A marginal albeit not significant difference between $D N M T 3 A^{\mathrm{wt}}$ and $D N M T 3 A^{\mathrm{mut}}$ expression (median value depicted; $p=$ 0.14). Statistical analysis was performed with the Mann-Whitney nonparametric test. wt wild type; mut mutant. shown in Table SIII. Mutations in human bone marrow cells were present at low VAFs of $23.1 \%$ and $6.3 \%$, respectively (Table 3). Each human sample was transplanted into three mice. After 8 months, bone marrow samples were isolated from recipient mice, representing an aging mouse model of the hematopoietic compartment. The first DNMT3A mutation with VAF of $23.1 \%$ remained stable during this time in all three recipient mice, with a median VAF of $21.8 \%$ (range, 10.8-30.8\%). The second DNMT3A mutation, initially present with a VAF of $6.3 \%$, displayed stable mutation kinetic in one mouse, whereas in the other two mice no mutation was detectable (Table 3).

\section{Discussion}

In this study, leukemia-associated mutations were frequently found in healthy elderly individuals. This confirms findings of recent exome-analysis studies who have shown age-related $\mathrm{CH}$ in healthy individuals, driven by mutations of genes recurrently mutated in myeloid neoplasms and associated with an increased risk of hematologic cancer and cardiovascular disease. All those studies identified similar genes, with the majority of mutations affecting epigenetic modifiers, such as DNMT3A, TET2, and ASXL1 [1-3, 13]. A recent whole-genome sequencing approach on a large population cohort from Iceland also supports the finding that $\mathrm{CH}$ is very common in elderly, both with and without candidate driver mutations, suggesting that age-related $\mathrm{CH}$ is inevitable [14]. Here, mutations were detected predominantly in epigenetic modifier genes DNMT3A, TET2, and $I D H 2$, which are known to promote self-renewal and 
Table 3 DNMT3A mutation rate in bone marrow of healthy individuals vs. mice xenografts.

\begin{tabular}{|c|c|c|c|c|}
\hline & \multirow[t]{2}{*}{ Individual A } & \multicolumn{3}{|c|}{ Mice xenografts ( 8 months after transplantation) } \\
\hline & & Mouse A1 & Mouse A2 & Mouse A3 \\
\hline \multicolumn{5}{|c|}{ DNMT3A ${ }^{\text {mut }}(\mathrm{S} 837 \mathrm{X})$} \\
\hline \multirow[t]{3}{*}{ VAF (\%) } & 23.1 & 23.8 & 10.8 & 30.8 \\
\hline & Individual B & \multicolumn{3}{|c|}{ Mice xenografts ( 8 months after transplantation) } \\
\hline & & Mouse B1 & Mouse B2 & Mouse B3 \\
\hline \multicolumn{5}{|c|}{$D_{N M T 3 A^{m u t}}(\mathrm{D} 768 \mathrm{H})$} \\
\hline VAF (\%) & 6.3 & 6.2 & 0 & 0 \\
\hline
\end{tabular}

$V A F$ variant allele frequency.

block differentiation of HSCs. These CHDMs are considered to be founder events in the evolution of myeloid diseases, such as acute myeloid leukemia (AML), myelodysplastic syndrome (MDS), chronic myelomonocytic leukemia (CMML), and myeloproliferative neoplasms (MPN) $[15,16]$. Defects in RNA splicing genes, such as $S F 3 B 1$, $S R S F 2$, and $U 2 A F 1$ have been described in pathogenesis of MDS [17], and were also detected within the cohort investigated.

In the study presented here, it was shown that mutation kinetics remain virtually stable over a 3 years follow-up. This suggests that detected CHDMs in healthy people enter a stage of clonal size stability for most people. A recent longitudinal study also showed temporal stability of mutated clones in healthy individuals [18], indicating an occurrence of these mutations in long-lived HSCs or committed progenitors. However, presence of these CHDMs, albeit in the form of the observed low-level cell clones, may increase the risk of acquiring additional mutations and represents the first step in potentially evolving leukemia. Individuals with CHIP have an 11-13 times increased risk of developing hematologic neoplasia, compared with the general population. This is because the acquisition of subsequent, disease driving mutations occurs at a much higher rate in people already affected by clonal expansion, initiated by early mutations. All-cause mortality was also observed with higher incidence among individuals with detectable $\mathrm{CH}$, possibly due to higher risk of death from cardiovascular disease [2, 3]. A recent study demonstrated almost the doubling of the risk of coronary heart disease in humans in case of CHIP in peripheral-blood cells [19]. However, the absolute risk of developing a malignant hematologic disease is low, with the rate of progression being $0.5-1 \%$ per year [4]. Further research should focus on the underlying mechanisms which transform clonal haematopoiesis from a seemingly common and benign to a relatively rare malignant state.

In the cohort of healthy elderly individuals DNMT3A mutations were the most frequent $(14 \% ; 7 / 50)$, with one person harboring two different DNMT3A mutations in independent clones. This is in accordance with previous studies, which also identified DNMT3A as one of the most frequently mutated epigenetic regulator genes [1-3]. Using a custom-designed highly sensitive DNMT3A NGS assay age-dependence of DNMT3A mutations was assessed. In the whole cohort of young and elderly healthy persons $(n=210), 10$ out of 13 DNMT3A mutations were detected in individuals older than 60 years, displaying an age-dependent increase of DNMT3A mutation prevalence. DNMT3A mutations are suggested to arise early in AML, leading to a clonally expanded pool of pre-leukemic HSCs [20]. Persistence of low-level DNMT3A mutations during remission in AML patients further supports the existence of pre-leukemic stem cells with CHDMs, which then represent a reservoir of pre-leukemic clones that can provoke a relapse [21].

Previous studies have shown that DNMT3A is among the most frequently mutated genes in AML, MPN, MDS, and adult-early T-cell precursor acute lymphoblastic leukemia (ETP-ALL) [16, 22-26]. Approximately 22\% of cytogenetically normal acute myeloid leukemia (CN-AML) patients carry a DNMT3A mutation, from which about $60 \%$ are localized in the catalytic domain, at the R882 hotspot $[22,27]$. These mutations exhibit dominantly negative functional effects, decreasing enzymatic activity, thus causing hypomethylation of target genes [28-30]. Their presence is correlated with an adverse outcome and a higher therapy-resistance rate in AML [22, 27]. Such hotspot mutations were also detected within the cohort of healthy individuals in this study, suggesting that they are an early event occurring in the pathogenesis of different hematological diseases.

Recent data further suggest a temporal hierarchy in DNMT3A and TET2 mutations' occurrence. Whereas DNMT3A mutations origin in multipotent stem cells, TET2 mutations occur mainly in myeloid cells [31]. Somatic mutations of DNMT3A and TET2 were also associated with accelerated atherosclerosis, thus increasing the risk of cardiovascular disease mediated by inflammatory mechanisms 
$[32,33]$. This finding indicates that CHDMs may predispose to both hematologic and non-hematologic diseases and might represent a valuable predictive and prognostic factor.

Furthermore, gene expression analysis showed significant age-dependent decrease of DNMT3A expression. This decrease is independent of the mutation status, implying that other factors apart from genomic alterations, such as changes in the bone marrow niche and an aging cellular background may play an important role in the DNMT3A expression rate and thus function. This is in correspondence with the higher prevalence of $\mathrm{CH}$ and hematologic malignancies in elderly [1-3]. Decreased DNMT3A expression rate with age may contribute to the bias of HSCs toward self-renewal, by affecting expression of downstream targets as shown by Challen et al. who found an upregulation of "HSC fingerprint" genes in DNMT3A-null HSCs [5]. These genes, such as NR4A2, PDK4, VASN, and PRDM16 are normally expressed in HSCs but not in differentiated blood cells [34], suggesting that $D N M T 3 A$ is required to suppress the stem cell program in HSCs to permit differentiation. Furthermore, multipotency genes including RUNX1, GATA3, PBX1, and CDKN1A were also highly expressed in DNMT3A-null HSCs, opposite to decreased expression of essential differentiation factors, such as those encoded by FLK2, IKAROS, SFPII, and MEF2C [5]. Taken together, altered expression of downstream target genes due to lower DNMT3A expression, resulting from mutations or other age-related factors, may promote $\mathrm{CH}$.

To further investigate the potential clonal selection of cells harboring DNMT3A mutations a mouse model was established. For that purpose, xenotransplantations of bone marrow cells from two healthy elderly patients with DNMT3A mutations were performed and the mutations' dynamics assessed over a period of 8 months. DNMT3A mutations displayed relatively stable kinetics. Mice xenografts from individual A, with an initial VAF of $23.1 \%$, displayed a median VAF of $21.8 \%$ (range: $10.8-30.8 \%$ ), showing stable kinetics. The initial VAF of $6.3 \%$ of individual $\mathrm{B}$ also remained stable in one out of three transplanted mice (median VAF 6.2\%). For the remaining two mice the mutational burden may have been below the detectability level of the pyrosequencing assay (5\%). Comparing this data with the longitudinal study on healthy individuals we can conclude that CHDMs, both in humans and a mouse model of aging hematopoiesis, are displaying relatively stable mutations kinetics, without clonal selection of the cells carrying mutations or progressing to overt hematological disease. This again suggests, that the presence of CHDMs itself is insufficient to initiate clonal selection and expansion without an additional influence of other intrinsic and/or extrinsic factors.

In conclusion, these findings indicate that the appearance of low-level clones with mutations in leukemia-associated genes is a common age-associated phenomenon. Occurrence of these mutations within epigenetic regulator genes and the RNA-splicing machinery may represent a premalignant condition in the development of hematologic cancers and predispose to other aging-associated disorders. DNMT3A mutations were the most common mutations identified in elderly individuals but were also apparent in younger healthy people, albeit less frequently. Further studies should investigate which compensatory mechanisms inhibit selection of cells carrying mutations, promoting a stage of clonal size stability in healthy elderly individuals in contrast to patients with overt myeloid disorders. Interestingly, this study shows an age-related decrease in DNMT3A expression and highlights that in addition to CHDMs, aberrant expression may be a feature of the aging hematopoietic system. Further studies should investigate whether other leukemia-associated genes show similar patterns.

Acknowledgements The excellent technical assistance of Mrs. Anja Waldau and Mrs. Susan Wittig is gratefully acknowledged. Open access funding provided by Projekt DEAL.

Funding DM and TE were supported by the Interdisciplinary Center for Clinical Research (IZKF, Universitätsklinikum Jena, Jena, Germany). FHH received funding by the Thuringian state program ProExzellenz (RegenerAging-FSU-I-03/14) of the Thuringian Ministry for Economics, Science and Digital Society (TMWWDG). Open access funding was provided by Projekt DEAL.

\section{Compliance with ethical standards}

Conflict of interest The authors declare that they have no conflict of interest.

Publisher's note Springer Nature remains neutral with regard to jurisdictional claims in published maps and institutional affiliations.

Open Access This article is licensed under a Creative Commons Attribution 4.0 International License, which permits use, sharing, adaptation, distribution and reproduction in any medium or format, as long as you give appropriate credit to the original author(s) and the source, provide a link to the Creative Commons license, and indicate if changes were made. The images or other third party material in this article are included in the article's Creative Commons license, unless indicated otherwise in a credit line to the material. If material is not included in the article's Creative Commons license and your intended use is not permitted by statutory regulation or exceeds the permitted use, you will need to obtain permission directly from the copyright holder. To view a copy of this license, visit http://creativecommons. org/licenses/by/4.0/.

\section{References}

1. Xie M, Lu C, Wang J, McLellan MD, Johnson KJ, Wendl MC, et al. Age-related mutations associated with clonal hematopoietic expansion and malignancies. Nat Med. 2014;20:1472-8.

2. Genovese G, Kahler AK, Handsaker RE, Lindberg J, Rose SA, Bakhoum SF, et al. Clonal hematopoiesis and blood-cancer risk inferred from blood DNA sequence. N Engl J Med. 2014;371: 2477-87. 
3. Jaiswal S, Fontanillas P, Flannick J, Manning A, Grauman PV, Mar BG, et al. Age-related clonal hematopoiesis associated with adverse outcomes. N Engl J Med. 2014;371:2488-98.

4. Steensma DP, Bejar R, Jaiswal S, Lindsley RC, Sekeres MA, Hasserjian RP, et al. Clonal hematopoiesis of indeterminate potential and its distinction from myelodysplastic syndromes. Blood. 2015;126:9-16.

5. Challen GA, Sun D, Jeong M, Luo M, Jelinek J, Berg JS, et al. Dnmt3a is essential for hematopoietic stem cell differentiation. Nat Genet. 2011;44:23-31.

6. Chomczynski P, Sacchi N. The single-step method of RNA isolation by acid guanidinium thiocyanate-phenolchloroform extraction: twenty-something years on. Nat Protoc. 2006;1:581-5.

7. Schafer V, Ernst J, Rinke J, Winkelmann N, Beck JF, Hochhaus A, et al. EZH2 mutations and promoter hypermethylation in childhood acute lymphoblastic leukemia. J Cancer Res Clin Oncol. 2016;142: 1641-50.

8. Rinke J, Schafer V, Schmidt M, Ziermann J, Kohlmann A, Hochhaus A, et al. Genotyping of 25 leukemia-associated genes in a single work flow by next-generation sequencing technology with low amounts of input template DNA. Clin Chem. 2013;59:1238-50.

9. Adzhubei IA, Schmidt S, Peshkin L, Ramensky VE, Gerasimova A, Bork P, et al. A method and server for predicting damaging missense mutations. Nat Methods. 2010;7:248-9.

10. Choi Y, Sims GE, Murphy S, Miller JR, Chan AP. Predicting the functional effect of amino acid substitutions and indels. PLoS ONE. 2012;7:e46688.

11. Livak KJ, Schmittgen TD. Analysis of relative gene expression data using real-time quantitative PCR and the 2(-Delta Delta C(T)) method. Methods. 2001;25:402-8.

12. Mohr J, Dash BP, Schnoeder TM, Wolleschak D, Herzog C, Tubio Santamaria N, et al. The cell fate determinant Scribble is required for maintenance of hematopoietic stem cell function. Leukemia. 2018;32:1211-21.

13. Score J, Chase A, Forsberg LA, Feng L, Waghorn K, Jones AV, et al. Detection of leukemia-associated mutations in peripheral blood DNA of hematologically normal elderly individuals. Leukemia. 2015;29:1600-2.

14. Zink F, Stacey SN, Norddahl GL, Frigge ML, Magnusson OT, Jonsdottir I, et al. Clonal hematopoiesis, with and without candidate driver mutations, is common in the elderly. Blood. 2017; 130:742-52.

15. Chiba S. Dysregulation of TET2 in hematologic malignancies. Int J Hematol. 2017;105:17-22.

16. Walter MJ, Ding L, Shen D, Shao J, Grillot M, McLellan M, et al. Recurrent DNMT3A mutations in patients with myelodysplastic syndromes. Leukemia. 2011;25:1153-8.

17. Haferlach T, Nagata Y, Grossmann V, Okuno Y, Bacher U, Nagae $\mathrm{G}$, et al. Landscape of genetic lesions in 944 patients with myelodysplastic syndromes. Leukemia. 2014;28:241-7.

18. Young AL, Challen GA, Birmann BM, Druley TE. Clonal haematopoiesis harbouring AML-associated mutations is ubiquitous in healthy adults. Nat Commun. 2016;7:12484.
19. Jaiswal S, Natarajan P, Silver AJ, Gibson CJ, Bick AG, Shvartz E, et al. Clonal hematopoiesis and risk of atherosclerotic cardiovascular disease. N Engl J Med. 2017;377:111-21.

20. Shlush LI, Zandi S, Mitchell A, Chen WC, Brandwein JM, Gupta $\mathrm{V}$, et al. Identification of pre-leukaemic haematopoietic stem cells in acute leukaemia. Nature. 2014;506:328-33.

21. Ploen GG, Nederby L, Guldberg P, Hansen M, Ebbesen LH, Jensen $\mathrm{UB}$, et al. Persistence of DNMT3A mutations at long-term remission in adult patients with AML. Br J Haematol. 2014;167:478-86.

22. Ley TJ, Ding L, Walter MJ, McLellan MD, Lamprecht T, Larson DE, et al. DNMT3A mutations in acute myeloid leukemia. N Engl J Med. 2010;363:2424-33.

23. Yan XJ, Xu J, Gu ZH, Pan CM, Lu G, Shen Y, et al. Exome sequencing identifies somatic mutations of DNA methyltransferase gene DNMT3A in acute monocytic leukemia. Nat Genet. 2011;43:309-15.

24. Yamashita Y, Yuan J, Suetake I, Suzuki H, Ishikawa Y, Choi YL, et al. Array-based genomic resequencing of human leukemia. Oncogene. 2010;29:3723-31.

25. Shih AH, Abdel-Wahab O, Patel JP, Levine RL. The role of mutations in epigenetic regulators in myeloid malignancies. Nat Rev Cancer. 2012;12:599-612.

26. Neumann M, Heesch S, Schlee C, Schwartz S, Gokbuget N, Hoelzer $\mathrm{D}$, et al. Whole-exome sequencing in adult ETP-ALL reveals a high rate of DNMT3A mutations. Blood. 2013;121:4749-52.

27. Guryanova OA, Shank K, Spitzer B, Luciani L, Koche RP, Garrett-Bakelman FE, et al. DNMT3A mutations promote anthracycline resistance in acute myeloid leukemia via impaired nucleosome remodeling. Nat Med. 2016;22:1488-95.

28. Kim SJ, Zhao H, Hardikar S, Singh AK, Goodell MA, Chen T. A DNMT3A mutation common in AML exhibits dominant-negative effects in murine ES cells. Blood. 2013;122:4086-9.

29. Russler-Germain DA, Spencer DH, Young MA, Lamprecht TL, Miller CA, Fulton R, et al. The R882H DNMT3A mutation associated with AML dominantly inhibits wild-type DNMT3A by blocking its ability to form active tetramers. Cancer Cell. 2014;25:442-54.

30. Yang L, Rau R, Goodell MA. DNMT3A in haematological malignancies. Nat Rev Cancer. 2015;15:152-65.

31. Buscarlet M, Provost S, Feroz Zada Y, Bourgoin V, Mollica L, Dube MP, et al. Lineage restriction analyses in CHIP indicate myeloid bias for TET2 and multipotent stem cell origin for DNMT3A. Blood 2018;132:277-80.

32. Fuster JJ, MacLauchlan S, Zuriaga MA, Polackal MN, Ostriker $\mathrm{AC}$, Chakraborty R, et al. Clonal hematopoiesis associated with TET2 deficiency accelerates atherosclerosis development in mice. Science (New York, NY). 2017;355:842-7.

33. Sano S, Ohshima K, Wang Y, Katanasaka Y, Sano M, Walsh K. CRISPR-mediated gene editing to assess the roles of Tet2 and Dnmt3a in clonal hematopoiesis and cardiovascular disease. Circ Res 2018;123:335-41.

34. Chambers SM, Boles NC, Lin KY, Tierney MP, Bowman TV, Bradfute SB, et al. Hematopoietic fingerprints: an expression database of stem cells and their progeny. Cell Stem Cell. 2007;1:578-91. 